Article

\title{
An Improved Crow Search Algorithm Applied to Energy Problems
}

\author{
Primitivo Díaz ${ }^{1, *(1)}$, Marco Pérez-Cisneros ${ }^{1, *(1)}$, Erik Cuevas ${ }^{1, *}$, Omar Avalos ${ }^{1, *(1)}$, \\ Jorge Gálvez $^{1, *}$, Salvador Hinojosa ${ }^{2, * \text { (D) }}$ and Daniel Zaldivar ${ }^{1, * \text { (ID) }}$ \\ 1 Departamento de Electrónica, Universidad de Guadalajara, CUCEI Av. Revolución 1500, \\ 44430 Guadalajara, Mexico \\ 2 Departamento de Ingeniería del Software e Inteligencia Artificial, Facultad Informática, \\ Universidad Complutense de Madrid, 28040 Madrid, Spain \\ * Correspondence: primitivo.diaz@academicos.cucei.udg.mx (P.D.); marco.perez@cucei.udg.mx (M.P.-C.); \\ erik.cuevas@cucei.udg.mx (E.C.); omar.avalos@cutonala.udg.mx (O.A.); jorge.galvez@cutonala.udg.mx (J.G.); \\ salvahin@ucm.es (S.H.); daniel.zaldivar@cucei.udg.mx (D.Z.); Tel.: +52-33-1114-1298 (E.C.)
}

Received: 2 February 2018; Accepted: 28 February 2018; Published: 6 March 2018

\begin{abstract}
The efficient use of energy in electrical systems has become a relevant topic due to its environmental impact. Parameter identification in induction motors and capacitor allocation in distribution networks are two representative problems that have strong implications in the massive use of energy. From an optimization perspective, both problems are considered extremely complex due to their non-linearity, discontinuity, and high multi-modality. These characteristics make difficult to solve them by using standard optimization techniques. On the other hand, metaheuristic methods have been widely used as alternative optimization algorithms to solve complex engineering problems. The Crow Search Algorithm (CSA) is a recent metaheuristic method based on the intelligent group behavior of crows. Although CSA presents interesting characteristics, its search strategy presents great difficulties when it faces high multi-modal formulations. In this paper, an improved version of the CSA method is presented to solve complex optimization problems of energy. In the new algorithm, two features of the original CSA are modified: (I) the awareness probability (AP) and (II) the random perturbation. With such adaptations, the new approach preserves solution diversity and improves the convergence to difficult high multi-modal optima. In order to evaluate its performance, the proposed algorithm has been tested in a set of four optimization problems which involve induction motors and distribution networks. The results demonstrate the high performance of the proposed method when it is compared with other popular approaches.
\end{abstract}

Keywords: evolutionary computation; Crow Search Algorithm (CSA); induction motors; distribution networks

\section{Introduction}

The efficient use of energy has attracted the attention in a wide variety of engineering areas due to its environmental consequences. Induction motors and distribution networks are two representative problems that have strong implications in the massive use of energy.

Induction motors are highly used in industries as electromechanical actuators due to advantages such as ruggedness, cheap maintenance, low cost and simple operation. However, the statistics shows that approximately $2 / 3$ of industrial energy is consumed by the induction motors [1,2]. This high rate of consumption has caused the need to improve their efficiency which is highly dependent on the configuration of their internal parameters. The identification of parameters for induction motors represents a challenging process due to their non-linearity. For this reason, the parameter identification of induction motors is currently considered an open research area within the engineering. As a 
consequence, several algorithms for parameter identification in induction motors have been proposed in the literature [3,4].

On the other hand, distribution networks represent an active research area in electrical systems. The distribution system along with generators and transmission are the three fundamentals components of a power system. Distribution networks are responsible of the loss in the $13 \%[5,6]$ of the generated energy. This loss of energy in distribution networks is mainly caused by lack of reactive power in the buses. Capacitor bank allocation in distribution networks have proved to reduce the loss of energy produced by the lack of reactive power. The problem of banks allocation can be formulated as a combinatorial optimization problem where the number of capacitors, their sizes and location have to be optimally selected for satisfying the system restrictions. Many techniques have been proposed to solve this combinatorial optimization problem, which can be classified in four main methods; analytical $[5,7,8]$, numerical [9,10], heuristic [11-13], and based on artificial intelligence [14,15]. A detailed study about the methods are described in [15-17].

From an optimization perspective, the problems of parameter identification in induction motors and capacitor allocation in distribution networks are considered extremely complex due to their non-linearity, discontinuity, and high multi-modality. These characteristics make difficult to solve them by using standard optimization techniques.

Metaheuristics techniques inspired by the nature have been widely used in recent years to solve many complex engineering problems with interesting results. These methods do not need continuity, convexity, differentiability or certain initial conditions, which represents an advantage over traditional techniques. Particularity parameter identification of induction motors and the capacitor allocation represent two important problems that can be translated as optimization tasks. They have been already faced by using metaheuristic techniques. Some examples include the gravitational search algorithm [18,19], bacterial foraging [20,21], crow search algorithm [14], particle swarm optimization [22-25], genetic algorithm [26,27], differential evolution [28-30], tabu search [31] and firefly [32].

The Crow Search Algorithm (CSA) [33] is a metaheuristic method where individuals emulates the intelligent behavior in a group of crows. Its published results demonstrate its capacity to solve several complex engineering optimization problems. Some examples include its application to image processing [34] and water resources [35]. In spite of its interesting results, its search strategy presents great difficulties when it faces high multi-modal formulations.

In this paper, an enhanced version of the CSA method is proposed to solve the high multi-modal problems of parameter identification in induction motors and capacitor allocation in distribution networks. In the new algorithm, called Improved Crow Search Algorithm (ICSA), two features of the original CSA are modified: (I) the awareness probability (AP) and (II) the random perturbation. With the purpose to enhance the exploration-exploitation ratio the fixed awareness probability (AP) value is replaced (I) by a dynamic awareness probability (DAP), which is adjusted according to the fitness value of each candidate solution. The Lévy flight movement is also incorporated to enhance the search capacities of the original random perturbation (II) of CSA. With such adaptations, the new approach preserves solution diversity and improves the convergence to difficult high multi-modal optima. To evaluate the potential of the proposed method a series of experiments are conducted. In one set of problems, the algorithm is applied to estimate the parameters of two models of induction motors. The other set, the proposed approach is tested in the 10-bus, 33-bus and 64-bus of distribution networks. The results obtained in the experiments are analyzed statistically and compared with related approaches.

The organization of the paper is as follows: Section 2 describes the original CSA, Section 3 the proposed ICSA is presented, Section 4 the motor parameter estimation problem is exposed, Section 5 the capacitor allocation problem is described and Section 6 present the experimental results. Finally, the conclusions are stated in Section 7. 


\section{Crow Search Algorithm (CSA)}

In this section, a general description of the standard CSA is presented. Crow search algorithm is a recent metaheuristic algorithm developed by Askarzadeh [33], which is inspired on the intelligence behavior of crows. In nature, crows evidence intelligence behaviors like self-awareness, using tools, recognizing faces, warn the flock of potentially unfriendly ones, sophisticated communication ways and recalling the food's hidden place after a while. All these conducts linked to the fact that the brain-body ratio of the crows is slightly lower than the human brain have made it recognized as one of the most intelligent birds in nature [36,37].

The CSA evolutionary process emulates the behavior conducted by crows of hiding and recovering the extra food. As an algorithm based on population, the size of the flock is conformed by $N$ individuals (crows) which are of $n$-dimensional with $n$ as the problem dimension. The position $X_{i, k}$ of the crow $i$ in a certain iteration $k$ is described in Equation (1) and represents a possible solution for the problem:

$$
X_{i, k}=\left[x_{i, k}^{1}, x_{i, k}^{2}, \ldots, x_{i, k}^{n}\right] ; i=1,2, \ldots, N ; k=1,2, \ldots, \max \text { Iter }
$$

where max Iter is the maximum of iterations in the process. Each crow (individual) is assumed to have the capability of remember the best visited location $M_{i, k}$ to hide food until the current iteration Equation (2):

$$
M_{i, k}=\left[m_{i, k}^{1}, m_{i, k}^{2}, \ldots, m_{i, k}^{n}\right]
$$

The position of each is modified according to two behaviors: Pursuit and evasion.

Pursuit: A crow $j$ follows crow $i$ with the purpose to discover its hidden place. The crow $i$ does not notice the presence of the other crow, as consequence the purpose of crow $j$ is achieve.

Evasion: The crow $i$ knows about the presence of crow $j$ and in order to protect its food, crow $i$ intentionally take a random trajectory. This behavior is simulated in CSA through the implementation of a random movement.

The type of behavior considered by each crow $i$ is determinate by an awareness probability (AP). Therefore, a random value $r_{i}$ uniformly distributed between 0 and 1 is sampled. If $r_{i}$ is greater or equal than $A P$, behavior 1 is applied, otherwise situation two is chosen. This operation can be summarized in the following model:

$$
X_{i, k+1}= \begin{cases}X_{i, k}+r_{i} \cdot f l_{i, k} \cdot\left(M_{j, k}-X_{i, k}\right) & r_{i} \geq A P \\ \text { random } & \text { otherwise }\end{cases}
$$

The flight length $f l_{i, k}$ parameter indicates the magnitude of movement from crow $X_{i, k}$ towards the best position $M_{j, k}$ of crow $j$, the $r_{i}$ is a random number with uniform distribution in the range [0,1].

Once the crows are modified, their position is evaluated and the memory vector is updated as follows:

$$
M_{i, k+1}= \begin{cases}F\left(X_{i, k+1}\right) & F\left(X_{i, k+1}\right)<F\left(M_{i, k}\right) \\ M_{i, k} & \text { otherwise }\end{cases}
$$

where the $F(\cdot)$ represents the objective function to be minimized.

\section{The Proposed Improved Crow Search Algorithm (ICSA)}

The CSA has demonstrated its potential to find the optimum solution for certain search spaces configurations $[14,33,38]$. However, its convergence is not guaranteed due to the ineffective exploration of its search strategy. Under this condition, its search strategy presents great difficulties when it faces high multi-modal formulations. In the original CSA method, two different elements are mainly responsible of the search process: The awareness probability $(A P)$ and the random movement (evasion). The value of $A P$ is the responsible of provide the balance between diversification and 
intensification. On the other hand, the random movement directly affects the exploration process through the re-initialization of candidate solutions. In the proposed ICSA method, both elements, the awareness probability $(A P)$ and the random movement, are reformulated.

\subsection{Dynamic Awareness Probability (DAP)}

The parameter $A P$ is chosen at the beginning of the original CSA method and remains fixed during the optimization process. This fact is not favorable to the diversification-intensification ratio. In order to improve this relation, the awareness probability $(A P)$ is substituted by a dynamic awareness probability $(D A P)$, which is a probability value adjusted by the fitness quality of each candidate solution. The use of probability parameters based on fitness values has been successfully adopted in the evolutionary literature [39]. Therefore, the dynamic awareness probability $(D A P)$ is computed as follows:

$$
D A P_{i, k}=0.9 \cdot \frac{F\left(X_{i, k}\right)}{w V}+0.1
$$

where $w V$ represents the worst fitness value seen so-far. Assuming a minimization problem, this value is calculated as follows $w V=\max \left(F\left(X_{j, k}\right)\right)$. Under this probabilistic approach, promising solutions will have a high probability to be exploited. On the other hand, solutions of bad quality will have a high probability to be re-initialized with a random position.

\subsection{Random Movement_Lévy Flight}

The original CSA emulates two different behaviors of crows: pursuit and evasion. The behavior of evasion is simulated by the implementation of a random movement which is computed through a random value uniformly distributed.

In nature, the use of strategies to find food is essential to survive. A search method that is not able to explore good sources of food may be fatal for the animal. Lévy flights, introduced by Paul Lévy in 1937, is a type of random walk which has been observed in many species as a foraging pattern [40-42]. In Lévy flights, the step size is controlled by a heavy-tailed probability distribution usually known as Lévy distribution. The Lévy Flights are more efficient exploring the search space than the uniform random distribution [43].

In the proposed ICSA, with the objective to have a better diversification on the search space, Lévy flights are used instead of uniform random movements to simulate the evasion behavior. Therefore, a new random position $X_{i, k+1}$ is generated adding to the current position $X_{i, j}$ the computed Lévy flight $L$.

To obtain a symmetric Lévy stable distribution for $L$ the Mantegna algorithm [44] is used. Under the Mantegna method, the first stage is to calculate the step size $Z_{i}$ as follows:

$$
Z_{i}=\frac{a}{|b|^{1 / \beta}}
$$

where $a$ and $b$ are $n$-dimensional vectors and $\beta=3 / 2$. The elements of each vector $a$ and $b$ are sampled from the normal distribution characterized by the following parameters:

$$
\begin{array}{cc}
a \sim N\left(0, \sigma_{a}^{2}\right) & b \sim N\left(0, \sigma_{b}^{2}\right) \\
\sigma_{a}=\left\{\frac{\Gamma(1+\beta) \sin (\pi \beta / 2)}{\Gamma[(1+\beta) / 2] \beta 2^{(\beta-1) / 2}}\right\}^{1 / \beta}, & \sigma_{b=1}
\end{array}
$$

where $\Gamma(\cdot)$ denotes a Gamma distribution. After obtaining the value of $Z_{i}$, the factor $L$ is calculated by the following model:

$$
L=0.01-Z_{i} \odot\left(X_{i, k}-X^{b e s t}\right)
$$

where the product $\odot$ implies the element-wise multiplications, $X^{\text {best }}$ represents the best solution seen so far in terms of the fitness quality. Finally, the new position $X_{i, k+1}$ is given by: 


$$
X_{i, k+1}=X_{i, k}+L
$$

The proposed ICSA algorithm is given in the form of a flowchart in Figure 1.

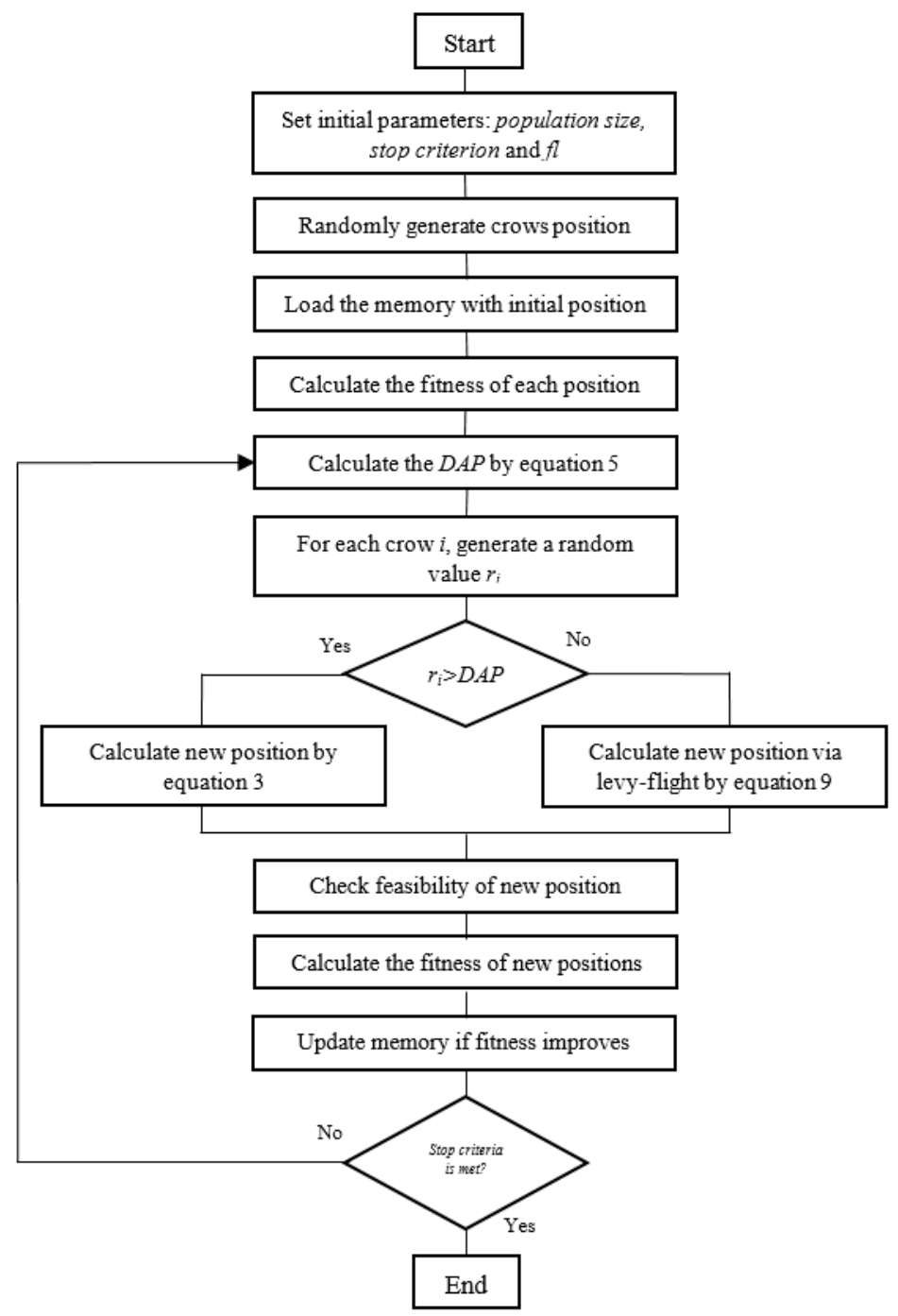

Figure 1. Flowchart of ICSA algorithm.

\section{Motor Parameter Estimation Formulation}

The physical characteristics of an inductor motor make it complicated to obtain the internal parameter values directly. A way to deal with this disadvantage is estimate them through identification methods. There are two different circuit models that allow a suitable configuration for estimate the motor parameters. The two models are the approximate circuit model and the exact circuit model [4]. The basic difference is the number of parameters included in the model.

The parameter estimation is faced as an $n$-dimensional optimization problem, where $n$ is the number of internal parameters of the induction motor. The goal is to minimize the error between the estimated parameters and the values provided by the manufacturer, adjusting the parameter values of the equivalent circuit. Under such conditions, the optimization process becomes a challenging task due to the multiple local minima produced with this approach. 


\subsection{Approximate Circuit Model}

The approximate circuit model characterizes an induction motor without considering the magnetizing and rotor reactance parameters. Thus, the accuracy is less than the exact circuit model.

Figure 2 presents the approximate circuit model. In the Figure, it is represented all the parameters used to characterize the motor such the stator resistance $\left(R_{s}\right)$, rotor resistance $\left(R_{r}\right)$, stator leakage reactance $\left(X_{s}\right)$ and motor slip $(m s)$ which are estimated using the data provided by the manufacture of starting torque $\left(T_{s t r}\right)$, maximum torque $\left(T_{\max }\right)$ and full load torque $\left(T_{f l}\right)$. Based on this model, the estimation task can be expressed as the following optimization problem:

$$
\begin{gathered}
\begin{array}{c}
\operatorname{minCost}_{A M}(\theta) \\
\text { Subject to }
\end{array} \quad \begin{array}{c}
\text { where } \theta=\left(R_{s}, R_{r}, X_{s}, m s\right) \\
\operatorname{Cost}_{A M}(\theta)=R_{r}, m s<1,0 \leq X_{s} \leq 10, \\
\sum_{i=1}^{3}\left(F_{i}(\theta)\right)^{2}
\end{array} \\
F_{1}(\theta)=\frac{\frac{K_{t} R_{r}}{m s\left[\left(R_{s}+\frac{R_{r}}{m s}\right)^{2}+X_{s}\right]}-T_{f l}}{T_{f l}} \\
F_{2}(\theta)=\frac{\frac{K_{t} R_{r}}{\left(R_{s}+R_{r}\right)^{2}+X_{s}}-T_{s t r}}{T_{s t r}} \\
F_{3}(\theta)=\frac{\frac{K_{t}}{2\left[R_{s}+\sqrt{R_{s}^{2}+X_{s}^{2}}\right]}-T_{\max }}{T_{\max }} \\
K_{t}=\frac{3 V_{p h}^{2}}{\omega_{s}}
\end{gathered}
$$

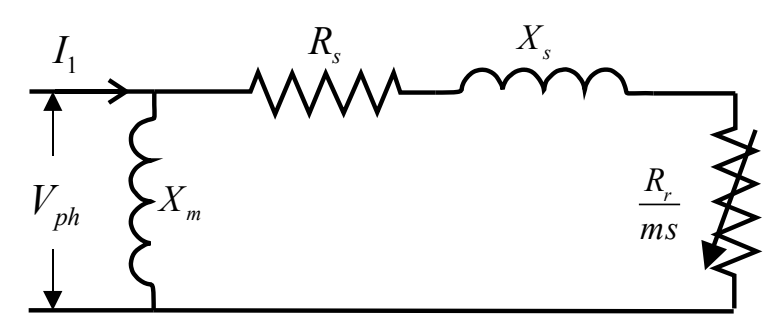

Figure 2. Approximate circuit model.

\subsection{Exact Circuit Model}

Different from the approximate circuit model, the exact circuit model characterizes the induction motor by using all the motor parameters. Figure 3 illustrates the exact circuit model. This circuit configuration includes the parameters stator resistance $\left(R_{s}\right)$, rotor resistance $\left(R_{r}\right)$, stator leakage inductance $\left(X_{s}\right)$ and motor slip $(m s)$ also add two more calculations, the rotor leakage reactance $\left(X_{r}\right)$ and the magnetizing leakage reactance $\left(X_{m}\right)$ to obtain, the maximum torque $\left(T_{\max }\right)$, full load torque $\left(T_{f l}\right)$, starting torque $\left(T_{s t r}\right)$ and full load power factor $(p f)$. Based on this exact circuit model, the estimation task can be formulated as the following optimization problem:

$$
\begin{array}{cc}
\operatorname{minCost}_{E M}(\theta) & \text { where } \theta=\left(R_{s}, R_{r}, X_{s}, m s, X_{r}, X_{m}\right) \\
\text { Subject to } & 0<R_{s}, R_{r}, X_{s}, m s, X_{r}<1,0<X_{m}<10 \frac{p_{f l}-\left(I_{1}^{2} R_{s}+I_{2}^{2} R_{r}+P_{r o t}\right)}{p_{f l}}=n_{f l}
\end{array}
$$


where $p_{f l}$ and $P_{\text {rot }}$ are the rated power and rotational losses, while $n_{f l}$ is the efficiency given by the manufacturer. The values of $p_{f l}$ and $P_{r o t}$ preserve compatibility with related works [3,18]:

$$
\begin{gathered}
\operatorname{Cost}_{A M}(\theta)=\sum_{i=1}^{4}\left(F_{i}(\theta)\right)^{2} \\
F_{1}(\theta)=\frac{\frac{K_{t} R_{r}}{m s\left[\left(R_{t h}+\frac{R_{r}}{m s}\right)^{2}+X^{2}\right]}-T_{f l}}{T_{f l}} \\
F_{2}(\theta)=\frac{\frac{K_{t} R_{r}}{\left(R_{t h}+R_{r}\right)^{2}+X^{2}}-T_{s t r}}{T_{s t r}} \\
F_{3}(\theta)=\frac{\frac{K_{t}}{2\left[R_{t h}+\sqrt{\left.R_{t h}^{2}+X^{2}\right]}-T_{\max }\right.}}{T_{\max } \times m f} \\
F_{4}(\theta)=\frac{\cos \left(\tan ^{-1}\left(\frac{X}{R_{t h}+\frac{R_{r}}{m s}}\right)\right)-p f}{p f} \\
V_{t h}=\frac{V_{p h} X_{m}}{X_{s}+X_{m}} \\
R_{t h}=\frac{R_{1} X_{m}}{X_{s}+X_{m}} \\
X_{t h}=\frac{X_{s} X_{m}}{X_{s}+X_{m}} \\
K_{t}=\frac{3 V_{p h}^{2}}{\omega_{s}} \\
X=X_{r}+X_{t h}
\end{gathered}
$$

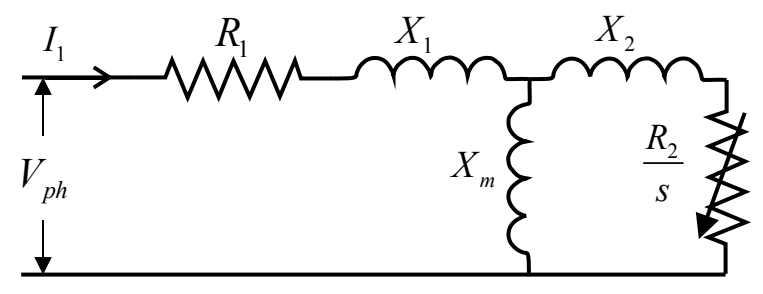

Figure 3. Exact Circuit Model.

\section{Capacitor Allocation Problem Formulation}

\subsection{Load Flow Analysis}

In this section the capacitor allocation problem is described. Therefore, in order to know the characteristics of voltage profile and power losses in a distribution network a load flow analysis is conducted. Several techniques have been considered to accomplish the analysis [45,46]. In this paper, for its simplicity, the method proposed in [47] has been adopted to find the voltages in all buses. Assuming the single line diagram of a three balanced distribution system, as shown in Figure 4, the values of voltage and power losses are calculated as follows:

$$
\left|V_{i+1}\right|=-\left[\frac{V_{i}^{2}}{2}-R_{i} \cdot P_{i+1}-X_{i} \cdot Q_{i+1}\right]+\left[\left(-\frac{V_{i}^{2}}{2}+R_{i} \cdot P_{i+1}+X_{i} \cdot Q_{i+1}\right)-\left(R_{i}^{2}+X_{i}^{2}\right) \cdot\left(P_{i}^{2}+Q_{i}^{2}\right)\right]^{1 / 2}
$$




$$
\begin{gathered}
P_{L i}=\frac{R_{i} \cdot\left[P_{i+1}^{2}+Q_{i+1}^{2}\right]}{\left|V_{i+1}^{2}\right|^{2}} \\
Q_{L i}=\frac{X_{i} \cdot\left[P_{i+1}^{2}+Q_{i+1}^{2}\right]}{\left|V_{i+1}^{2}\right|^{2}} \\
P_{\text {LOSS }}=\sum_{i=1}^{N} P_{L i}
\end{gathered}
$$

where $\left|V_{i+1}\right|$ is the voltage magnitude in the $i$-th +1 node, $R_{i}$ and $X_{i}$ are the resistance and the reactance in the branch $i . P_{i+1}$ and $Q_{i+1}$ are the real and reactive power load flowing through node $i$-th $+1, P_{L i}$ and $Q_{L i}$ are the real and reactive power losses at node $i$, while $P_{L O S S}$ is the total real loss in the network.

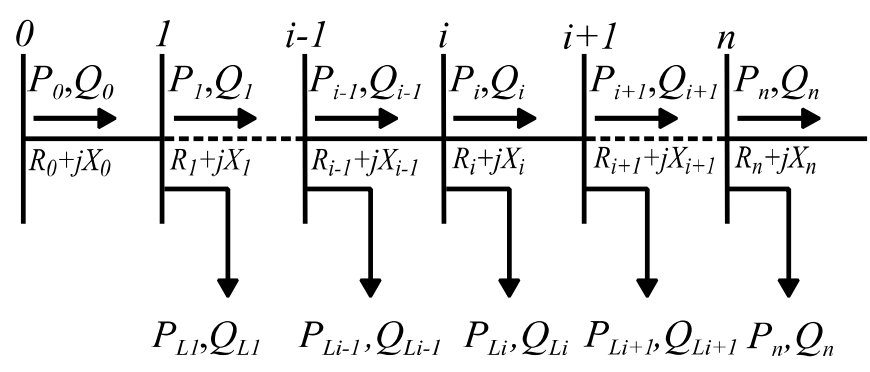

Figure 4. Simple radial distribution system.

\subsection{Mathematical Approach}

The optimal allocation of capacitors in distribution network buses is represented by the solution that minimize the annual cost generated by power losses of the whole system (Equation (31)), as well as the cost of capacitor installation (Equation (32)):

$$
\begin{aligned}
& \text { Min AC }=k_{p} \cdot P_{\text {LOSS }} \\
& \text { Min IC }=\sum_{i=i}^{N} k_{i}^{c} \cdot Q_{i}^{c},
\end{aligned}
$$

where $A C$ is the annual cost generated by the real power losses, $k_{p}$ is the price of losses in $\mathrm{kW}$ per year, $P_{\text {LOSS }}$ is the total of real power losses in the system, IC represents the installation cost of each capacitor, $N$ corresponds to the number of buses chosen for a capacitor installation, $k_{i}^{c}$ is the cost per $\mathrm{kVar}$, and $Q_{i}^{c}$ is the size of capacitor in bus $i$. The maintenance capacitor cost is not included in the objective function.

Therefore, the general objective function can be expressed as follows:

$$
\operatorname{Min} F=A C+I C
$$

The minimization of the objective function $F$ is subject to certain voltage constraints given by:

$$
V_{\min } \leq\left|V_{i}\right| \leq V_{\max }
$$

where $V_{\min }=0.90$ p.u. and $V_{\max }=1.0$ p.u. are the lower and upper limits of voltages, respectively. $\left|V_{i}\right|$ represents the voltage magnitude in bus $i$.

Under such conditions, in the optimization process, an optimal selection of size, type, number and location of capacitors must be found. This problem is considered a complex optimization task for this reason the proposed ICSA is used to solve it. 


\subsection{Sensitivity Analysis and Loss Sensitivity Factor}

Sensitivity analysis is a technique applied mainly to reduce the search space. The idea is to provide knowledge about the parameters in order to lessen the optimization process. In capacitor allocation problem, the sensitivity analysis is used to obtain the parameters with less variability [48]. This information allows to know the nodes that can be considered as potential candidates to allocate a capacitor. Under such conditions, the search space can be reduced. In addition, the nodes identified with less variability correspond to those which will have greater loss reduction with the capacitor installation.

Assuming a simple distribution line from Figure 4, as is shown in Figure 5, the equations of active power loss and reactive power loss (Equations (28)-(29)) can be rewritten as follows:

$$
\begin{gathered}
P_{\text {Lineloss }}(i+1)=\frac{\left(P_{e f f}^{2}(i+1)+Q_{e f f}^{2}(i+1)\right) \cdot R(i)}{V^{2}(i+1)} \\
Q_{\text {Lineloss }}(i+1)=\frac{\left(P_{\text {eff }}^{2}(i+1)+Q_{e f f}^{2}(i+1)\right) \cdot X(i)}{V^{2}(i+1)}
\end{gathered}
$$

where the term $P_{\text {eff }}(i+1)$ correspond to the total effective active power presented further the node $i+1$, and $Q_{\text {eff }}(i+1)$ is equivalent to the effective value of reactive power supplied further the node $i+1$.

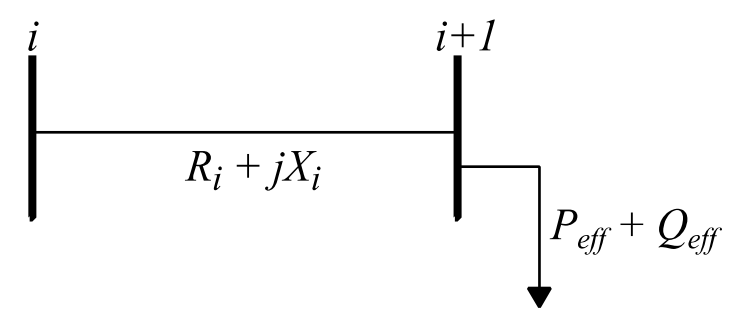

Figure 5. Simple Distribution Line.

Therefore, the loss sensitivity factors now can be obtained from Equations (35) and (36) as follows:

$$
\begin{gathered}
\frac{\partial P_{\text {Lineloss }}}{\partial Q_{\text {eff }}}=\frac{2 \cdot Q_{e f f}(i+1) \cdot R(i)}{V^{2}(i+1)} \\
\frac{\partial Q_{\text {Lineloss }}}{\partial Q_{e f f}}=\frac{2 \cdot Q_{e f f}(i+1) \cdot X(i)}{V^{2}(i+1)}
\end{gathered}
$$

Now, the processes to detect the possible candidate nodes is summarized in the next steps:

Step 1. Using Equation (25) to compute the Loss Sensitivity Factors for all nodes.

Step 2. Sort in descending order the Loss Sensitivity Factors and its corresponding node index.

Step 3. Calculate the normalized voltage magnitudes for all nodes using:

$$
\operatorname{norm}(\mathrm{i})=\frac{V(i)}{0.95}
$$

Step 4. Set a node as possible candidate those nodes whose norm value (calculated in the previous step) is less than 1.01.

\section{Experiments}

In order to evaluate the proposed method, a set of experiments are conducted considering two energy problems. The first experiment is the internal parameter estimation of two induction motor 
models. The second experiment is implemented over three distribution networks where the objective is to obtain the optimal capacitor allocation for reducing the power losses and improving the voltage profile. The experiments have been executed on a Pentium dual-core computer with a $2.53 \mathrm{GHz} \mathrm{CPU}$ and 8-GB RAM.

\subsection{Motor Parameter Estimation Test}

The performance of the proposed ICSA is tested over two induction motors with the purpose to estimate their optimal parameters. In the experimental process, the approximate $\left(\operatorname{Cost}_{A M}\right)$ and exact $\left(\operatorname{Cost}_{E M}\right)$ circuit model are used. The manufacturer characteristics of the motors are presented in Table 1.

Table 1. Manufacturer's motor data.

\begin{tabular}{ccc}
\hline Characteristics & Motor 1 & Motor 2 \\
\hline Power, HP & 5 & 40 \\
Voltage, $\mathrm{V}$ & 400 & 400 \\
Current, A & 8 & 45 \\
Frequency, Hz & 50 & 50 \\
No. Poles & 4 & 4 \\
Full load split & 0.07 & 0.09 \\
Starting torque $\left(T_{\text {str }}\right)$ & 15 & 260 \\
Max. Torque $\left(T_{\max }\right)$ & 42 & 370 \\
Stator current & 22 & 180 \\
Full load torque $\left(T_{f l}\right)$ & 25 & 190 \\
\hline
\end{tabular}

In the test, the results of the proposed ICSA method is compared to those presented by the popular algorithms DE, ABC and GSA. The parameters setting of the algorithms has been used in order to maintain compatibility with other works reported in the literature $[18,19,28,49]$ and are shown in Table 2.

Table 2. Algorithms Parameters.

\begin{tabular}{cccc}
\hline DE & ABC & GSA & ICSA \\
\hline$C R=0.5$ & $\varphi_{n i}=0.5$ & Go $=100$ & FL $=2.0$ \\
$F=0.2$ & $S N=120$ & Alpha $=20$ & \\
\hline
\end{tabular}

The tuning parameter $F L$ in the ICSA algorithm is selected as result of a sensitivity analysis which through experimentally way evidence the best parameter response. Table 3 shows the sensitivity analysis of the two energy problems treated in this work.

In the comparison, the algorithms are tested with a population size of 25 individuals, with a maximum number of generations established in 3000 . This termination criterion as well as the parameter setting of algorithms has been used to maintain concordance with the literature $[18,28,49]$. Additionally, the results are analyzed and validated statistically through the Wilcoxon test.

The results for the approximate model $\left(\operatorname{Cost}_{A M}\right)$ produced by motor 1 and motor 2 are presented in Tables 4 and 5, respectively. In the case of exact model $\left(\operatorname{Cost}_{E M}\right)$ the values of standard deviation and mean for the algorithms are shown in Table 6 for motor 1 and the results for motor 2 in Table 7. The results presented are based on an analysis of 35 independent executions for each algorithm. The results demonstrate that the proposed ICSA method is better than its competitors in terms of accuracy (Mean) and robustness (Std.). 
Table 3. Sensitivity Analysis of FL parameter.

\begin{tabular}{|c|c|c|c|c|c|c|}
\hline Parameter & Analysis & $\begin{array}{c}\text { Motor } 2 \\
\text { Exact Model }\end{array}$ & $\begin{array}{c}\text { Motor } 2 \\
\text { Approximate Model }\end{array}$ & 10-Bus & 33-Bus & 69-Bus \\
\hline \multirow{4}{*}{$F L=1.0$} & Min & $7.1142 \times 10^{-3}$ & $1.4884 \times 10^{-13}$ & 696.61 & 139.92 & 145.87 \\
\hline & Max & $1.1447 \times 10^{-2}$ & $2.6554 \times 10^{-5}$ & 699.56 & 146.06 & 164.12 \\
\hline & Mean & $7.2753 \times 10^{-3}$ & $1.6165 \times 10^{-5}$ & 697.22 & 140.52 & 147.89 \\
\hline & Std. & $7.4248 \times 10^{-4}$ & $5.6961 \times 10^{-5}$ & 0.6749 & 1.4291 & 3.2862 \\
\hline \multirow{4}{*}{$F L=1.5$} & Min & $7.1142 \times 10^{-3}$ & 0.0000 & 696.61 & 139.42 & 146.08 \\
\hline & Max & $7.2485 \times 10^{-3}$ & $2.6172 \times 10^{-3}$ & 701.03 & 144.55 & 161.03 \\
\hline & Mean & $7.1237 \times 10^{-3}$ & $7.47886 \times 10^{-5}$ & 697.65 & 140.70 & 147.54 \\
\hline & Std. & $2.5728 \times 10^{-5}$ & $4.4239 \times 10^{-4}$ & 0.8045 & 1.9417 & 2.8354 \\
\hline \multirow{4}{*}{$F L=2.0$} & Min & $7.1142 \times 10^{-3}$ & 0.0000 & 696.61 & 139.21 & 145.77 \\
\hline & Max & $7.1142 \times 10^{-3}$ & $1.1675 \times 10^{-25}$ & 698.07 & 140.31 & 156.36 \\
\hline & Mean & $7.1142 \times 10^{-3}$ & $3.4339 \times 10^{-27}$ & 696.76 & 139.49 & 146.20 \\
\hline & Std. & $2.2919 \times 10^{-11}$ & $1.9726 \times 10^{-26}$ & 0.3808 & 1.9374 & 2.1202 \\
\hline \multirow{4}{*}{$F L=2.5$} & Min & $7.1142 \times 10^{-3}$ & $4.3700 \times 10^{-27}$ & 696.82 & 140.40 & 145.91 \\
\hline & $\operatorname{Max}$ & $7.1170 \times 10^{-3}$ & $2.3971 \times 10^{-16}$ & 698.76 & 148.80 & 158.72 \\
\hline & Mean & $7.1142 \times 10^{-3}$ & $1.7077 \times 10^{-17}$ & 697.89 & 141.21 & 147.49 \\
\hline & Std. & $5.3411 \times 10^{-7}$ & $5.0152 \times 10^{-17}$ & 0.5282 & 2.069 & 2.5549 \\
\hline \multirow{4}{*}{$F L=3.0$} & Min & $7.1142 \times 10^{-3}$ & $6.8124 \times 10^{-21}$ & 696.78 & 140.45 & 145.96 \\
\hline & Max & $7.1121 \times 10^{-3}$ & $2.9549 \times 10^{-13}$ & 703.36 & 158.66 & 164.12 \\
\hline & Mean & $7.1142 \times 10^{-3}$ & $1.3936 \times 10^{-14}$ & 697.25 & 141.40 & 147.32 \\
\hline & Std. & $1.5398 \times 10^{-7}$ & $5.1283 \times 10^{-14}$ & 1.6921 & 3.309 & 3.2862 \\
\hline
\end{tabular}

Table 4. Results of approximate circuit model $\left(\operatorname{Cos}_{A M}\right)$, for motor 1.

\begin{tabular}{ccccc}
\hline Analysis & DE & ABC & GSA & ICSA \\
\hline Mean & $1.5408 \times 10^{-4}$ & 0.0030 & $5.4439 \times 10^{-21}$ & $1.9404 \times 10^{-30}$ \\
Std. & $7.3369 \times 10^{-4}$ & 0.0024 & $4.1473 \times 10^{-21}$ & $1.0674 \times 10^{-29}$ \\
Min & $1.9687 \times 10^{-15}$ & $2.5701 \times 10^{-5}$ & $3.4768 \times 10^{-22}$ & $1.4024 \times 10^{-32}$ \\
Max & 0.0043 & 0.0126 & $1.6715 \times 10^{-20}$ & $6.3192 \times 10^{-29}$ \\
\hline
\end{tabular}

Table 5. Results of approximate circuit model $\left(\operatorname{Cos}_{A M}\right)$, for motor 2.

\begin{tabular}{ccccc}
\hline Analysis & DE & ABC & GSA & ICSA \\
\hline Mean & $4.5700 \times 10^{-4}$ & 0.0078 & $5.3373 \times 10^{-19}$ & $3.4339 \times 10^{-27}$ \\
Std. & 0.0013 & 0.0055 & $3.8914 \times 10^{-19}$ & $1.9726 \times 10^{-26}$ \\
Min & $1.1369 \times 10^{-13}$ & $3.6127 \times 10^{-4}$ & $3.7189 \times 10^{-20}$ & 0.0000 \\
Max & 0.0067 & 0.0251 & $1.4020 \times 10^{-18}$ & $1.1675 \times 10^{-25}$ \\
\hline
\end{tabular}

Table 6. Results of exact circuit model $\operatorname{Cost}_{E M}$ for motor 1.

\begin{tabular}{ccccc}
\hline Analysis & DE & ABC & GSA & ICSA \\
\hline Mean & 0.0192 & 0.0231 & 0.0032 & 0.0019 \\
Std. & 0.0035 & 0.0103 & 0.0000 & $4.0313 \times 10^{-16}$ \\
Min & 0.0172 & 0.0172 & 0.0032 & 0.0019 \\
Max & 0.0288 & 0.0477 & 0.0032 & 0.0019 \\
\hline
\end{tabular}

Table 7. Results of exact circuit model Cost $t_{E M}$ for motor 2.

\begin{tabular}{ccccc}
\hline Analysis & DE & ABC & GSA & ICSA \\
\hline Mean & 0.0190 & 0.0791 & 0.0094 & 0.0071 \\
Std. & 0.0057 & 0.0572 & 0.0043 & $2.2919 \times 10^{-11}$ \\
Min & 0.0091 & 0.0180 & 0.0071 & 0.0071 \\
Max & 0.0305 & 0.2720 & 0.0209 & 0.0071 \\
\hline
\end{tabular}


The comparison of the final fitness values of different approaches is not enough to validate a new proposal. Other additional test also represents the convergence graphs. They show the evolution of the solutions through the optimization process. Therefore, they indicate which approaches reach faster the optimal solutions. Figure 6 shows the convergence comparison between the algorithms in logarithmic scale for a better appreciation, being the proposed method which present a faster to achieve the global optimal.

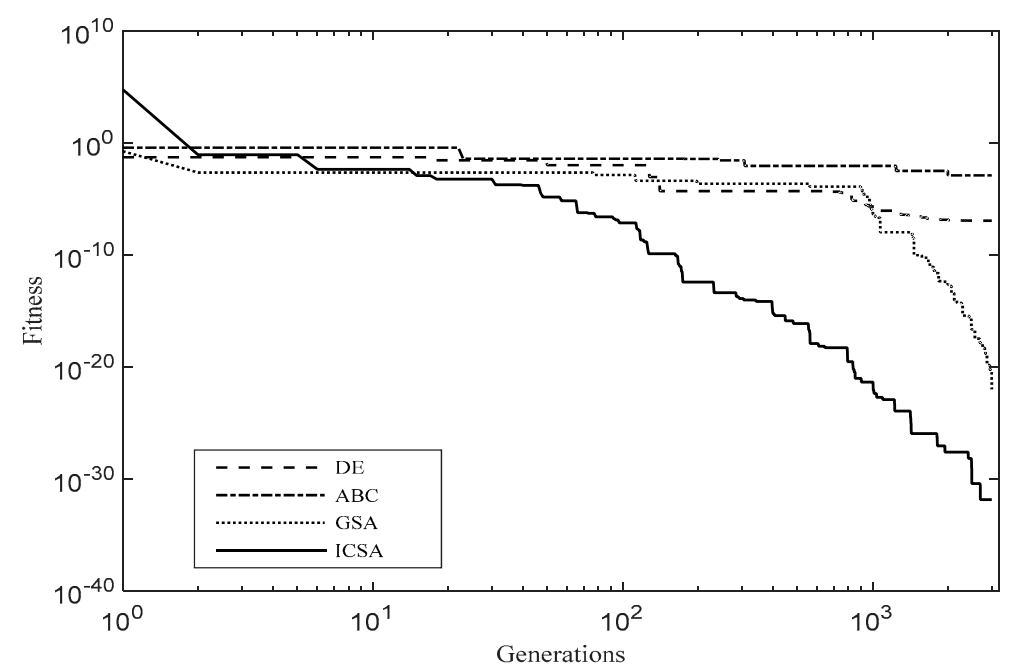

Figure 6. Convergence evolution comparison of approximate model $\left(\operatorname{Cost}_{A M}\right)$ for motor 1.

\subsection{Capacitor Allocation Test}

With the purpose to prove the performance of the proposed method a set of three distribution networks, the 10-bus [50], 33-bus [51], and 69-bus [52] is used in this experiment.

In the experiments, the algorithms DE, ABC, GSA has been used for comparison. Their setting parameters are shown in Table 2. For all algorithms the number of search agents and the maximum number of iterations is 25 and 100.

\subsubsection{0-Bus System}

The first distribution network comprises a 10-bus system with nine lines. This bus, shown in Figure 7, is considered as a substation bus. Table A1 in the Appendix A shows the system specifications of resistance and reactance of each line, as well as the real and reactive loads for each bus. The system presents a total active and reactive power load of $12,368 \mathrm{~kW}$ and $4186 \mathrm{kVAr}$, while the voltage supplied by the substation is $23 \mathrm{kV}$.

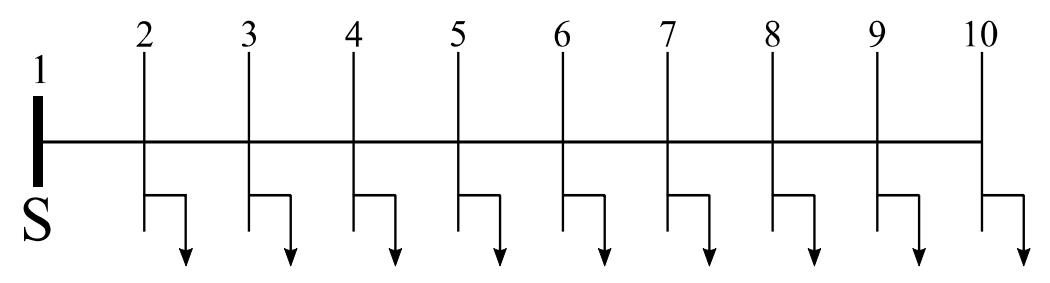

Figure 7. 10-bus distribution test system.

The network in uncompensated mode i.e., before allocating any capacitor, has a total power loss of $783.77 \mathrm{~kW}$, the minimum voltage is 0.8404 p.u. located at 10 th bus and the maximum is $0.9930 \mathrm{p.u}$. at 2nd bus. The cost per $\mathrm{kW}$ lost for this experiment and the remainders is $\$ 168$ with a loss of $783.77 \mathrm{~kW}$, while the annual cost is $\$ 131,674$. At beginning of the methodology, the sensitivity analysis is used to 
identify the candidate nodes with a high probability to install a capacitor. In case of the 10-bus, the buses $6,5,9,10,8$ and 7 are considered as candidates. Based on a set of 27 standard capacitor sizes and their corresponding annual price per KVAr, Table 8 shows the capacitor installation in each candidate node obtained by ICSA. After the optimization process the corresponding capacitor sizes are 1200, $3900,150,600,450 \mathrm{kVAr}$ installed in the optimal buses $6,5,9,10,8$. The total power loss is $696.76 \mathrm{~kW}$ with an annual cost of $\$ 117,055.68$. The comparison results obtained by the algorithms are shown in Table 9. Figure 8 illustrates the convergence evolution of the all algorithms.

Table 8. Possible capacitor sizes and cost (\$/kVAr).

\begin{tabular}{cccccccccc}
\hline $\mathbf{j}$ & $\mathbf{1}$ & $\mathbf{2}$ & $\mathbf{3}$ & $\mathbf{4}$ & $\mathbf{5}$ & $\mathbf{6}$ & $\mathbf{7}$ & $\mathbf{8}$ & $\mathbf{9}$ \\
\hline $\mathrm{Q}$ & 150 & 350 & 450 & 600 & 750 & 900 & 1050 & 1200 & 1350 \\
$\$ / \mathrm{kVAr}$ & 0.500 & 0.350 & 0.253 & 0.220 & 0.276 & 0.183 & 0.228 & 0.170 & 0.207 \\
$\mathrm{j}$ & 10 & 11 & 12 & 13 & 14 & 15 & 16 & 17 & 18 \\
$\mathrm{Q}$ & 1500 & 1650 & 1800 & 1950 & 2100 & 2250 & 2400 & 2550 & 2700 \\
$\$ / \mathrm{kVAr}$ & 0.201 & 0.193 & 0.187 & 0.211 & 0.176 & 0.197 & 0.170 & 0.189 & 0.187 \\
$\mathrm{j}$ & 19 & 20 & 21 & 22 & 23 & 24 & 25 & 26 & 27 \\
$\mathrm{Q}$ & 2850 & 3000 & 3150 & 3300 & 3450 & 3600 & 3750 & 3900 & 4050 \\
$\$ / \mathrm{kVAr}$ & 0.183 & 0.180 & 0.195 & 0.174 & 0.188 & 0.170 & 0.183 & 0.182 & 0.179 \\
\hline
\end{tabular}

Table 9. Experimental results of 10-bus system.

\begin{tabular}{|c|c|c|c|c|c|}
\hline \multirow{2}{*}{ Items Algorithms } & \multirow{2}{*}{ Base Case } & \multicolumn{4}{|c|}{ Compensated } \\
\hline & & DE & $\mathrm{ABC}$ & GSA & ICSA \\
\hline Total Power Losses $\left(P_{\text {LOSS }}\right), \mathrm{kW}$ & 783.77 & 700.24 & 697.18 & 699.67 & 696.76 \\
\hline Total Power losses cost, $\$$ & $131,673.36$ & $117,640.32$ & $117,126.24$ & $117,544.56$ & $117,055.68$ \\
\hline Optimal buses & - & $6,5,9,10$ & $6,5,10,8$ & $6,5,9,10,7$ & $6,5,9,10,8$ \\
\hline Optimal capacitor size & - & $\begin{array}{c}900,4050,600 \\
600\end{array}$ & $\begin{array}{c}1200,4050,600 \\
600\end{array}$ & $\begin{array}{c}1650,3150,600 \\
450,150\end{array}$ & $\begin{array}{c}1200,3900,150, \\
600,450\end{array}$ \\
\hline Total kVAr & - & 6150 & 6450 & 6000 & 6300 \\
\hline Capacitor cost, $\$$ & - & 1153.65 & 1192.95 & 1253.55 & 1189.8 \\
\hline Total annual cost & $131,673.36$ & $118,793.97$ & $118,329.19$ & $118,798.11$ & $118,245.48$ \\
\hline Net saving, \$ & - & $12,879.38$ & $13,344.17$ & $12,875.24$ & $13,427.88$ \\
\hline$\%$ saving & & 9.78 & 10.10 & 9.77 & 10.19 \\
\hline Minimum voltage, p.u. & 0.8375 (bus 10) & 0.9005 (bus 10) & 0.9001 (bus 10) & 0.9002 (bus 10) & 0.9000 (bus 10) \\
\hline Maximum voltage, p.u. & 0.9929 (bus 2) & 0.9995 (bus 3) & 1.0001 (bus 3) & 0.9992 (bus 3) & 0.9997 (bus 3) \\
\hline
\end{tabular}

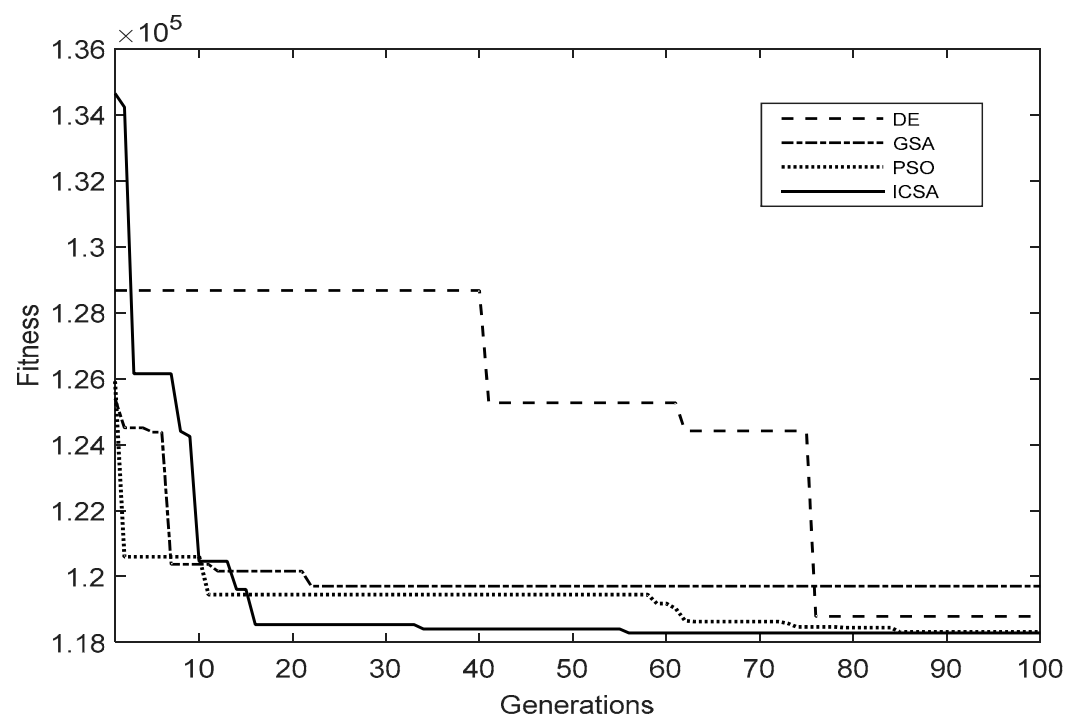

Figure 8. Convergence comparison 10-bus. 


\section{CSA vs. ICSA}

In order to compare directly the original CSA version with the proposed ICSA, the same experiments conducted in [14] have been considered. In the first experiment, the optimization process involves only the candidate buses of 5, 6 and 10 for capacitor allocation. The second test considers all the buses as possible candidates (except the substation bus) for capacitor installation. For the first experiment, all the possible capacitor combinations are $(27+1)^{3}=21952$. Under such conditions, it is possible to conduct a brute-force search for obtaining the global best. For this test, both algorithms (CSA and ICSA) have been able to achieve the global minimum.

In the second experiment, all buses are candidates for capacitor allocation. Under this approach, there are $(27+1)^{9}=1.0578 \times 10^{13}$ different combinations. In this scenario, a brute-force strategy is computationally expensive. The results of these experiments are shown in Table 10.

Table 10. Experiments results of ICSA over CSA in 10-bus system.

\begin{tabular}{|c|c|c|c|c|c|}
\hline Items Algorithms & Base Case & \multicolumn{2}{|c|}{ Experiment 1} & \multicolumn{2}{|c|}{ Experiment 2} \\
\hline Total Power Losses $\left(P_{\text {LOSS }}\right), \mathrm{kW}$ & 783.77 & 698.14 & 698.14 & 676.02 & 675.78 \\
\hline Optimal buses & - & $5,6,10$ & $5,6,10$ & $3,4,5,6,7,10$ & $3,4,5,6,8,10$ \\
\hline Optimal capacitor size & - & $4050,1650,750$ & $4050,1650,750$ & $\begin{array}{c}4050,2100,1950 \\
900,450,600\end{array}$ & $\begin{array}{c}4050,2400,1650, \\
1200,450,450\end{array}$ \\
\hline Total annual cost & - & $118,537.92$ & $118,537.92$ & $115,487.91$ & $115,414.14$ \\
\hline Net saving, \$ & $131,673.36$ & $13,135.43$ & $13,135.43$ & $16,185.44$ & $16,259.21$ \\
\hline \% saving & - & 9.9 & 9.9 & 12.29 & 12.35 \\
\hline Minimum voltage, p.u. & 0.8375 (bus 10) & 0.9000 (bus 10) & 0.9000 (bus 10) & 0.9003 (bus 10) & 0.9000 (bus 10) \\
\hline Maximum voltage, p.u. & 0.9929 (bus 2) & 1.0001 (bus 3) & 1.0001 (bus 3) & 1.0070 (bus 3) & 1.0070 (bus 3) \\
\hline
\end{tabular}

\subsubsection{3-Bus System}

In this experiment, a system with 33 buses and 32 lines is considered. In the system, the first bus is assumed as substation bus with a voltage of $12.66 \mathrm{kV}$. The network configuration is illustrated in Figure 9.

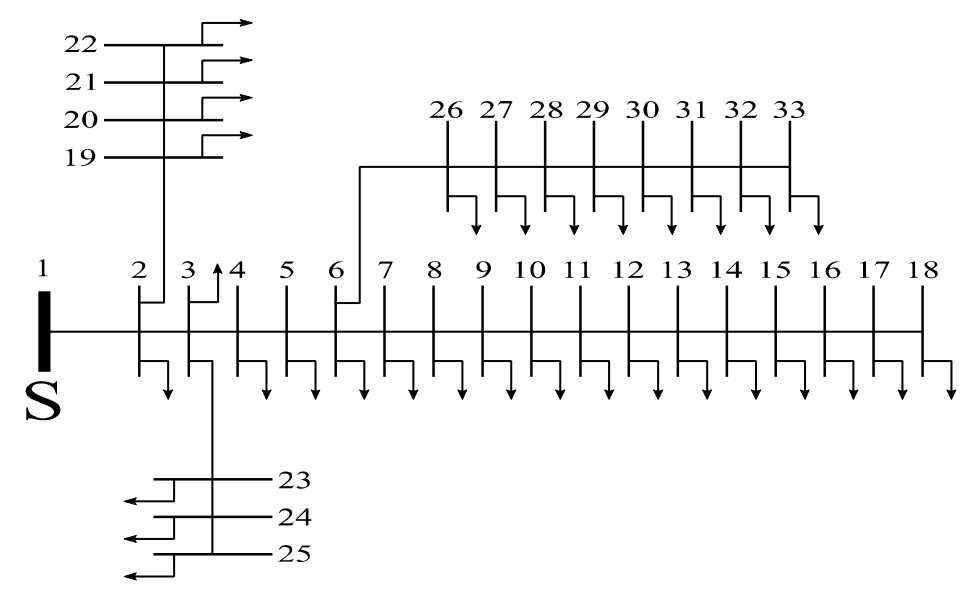

Figure 9. 33-Bus distribution test system.

The information about line resistance and reactance, as well as the corresponding load profile is shown in the Appendix A in Table A2. The 33-bus distribution network before the capacitor installation presents a total power loss of $210.97 \mathrm{~kW}$ with an annual cost of $\$ 35,442.96$ and a total active power of $3715 \mathrm{~kW}$. 
Once the optimization process is conducted, the buses 6, 30,13 are selected as the optimal location with the corresponding sizes of 450, 900, $350 \mathrm{kVAr}$. The candidate buses are determined by the sensitivity analysis. The total power loss after the capacitor installation is decreased from 210.91 to $138.74 \mathrm{~kW}$, saving $32.59 \%$ of the original cost. The results of the test in detail and the comparison between the algorithms are shown in Table 11. Figure 10 illustrates the convergence evolution of the all algorithms.

Table 11. Experimental results of 33-bus system.

\begin{tabular}{cccccc}
\hline \multirow{2}{*}{ Items Algorithms } & \multirow{2}{*}{ Base Case } & \multicolumn{4}{c}{ Compensated } \\
\cline { 3 - 6 } & & DE & ABC & GSA & ICSA \\
\cline { 3 - 6 } & 210.97 & 152.92 & 141.13 & 140.27 & 139.49 \\
Total Power Losses $\left(P_{\text {LOSS }}\right), \mathrm{kW}$ & $35,442.96$ & $25,690.56$ & $23,740.08$ & $23,565.60$ & $23,434.32$ \\
Total Power losses cost, \$ & - & $6,29,30,14$ & $6,29,8,13,27,31,14$ & $30,26,15$ & $30,7,12,15$ \\
Optimal buses & - & $350,750,350$, & $150,150,150,150$, & $900,450,350$ & $900,600,150$, \\
Optimal capacitor size & - & 750 & $600,450,150$ & 150 \\
Total kVAr & - & 2200 & 1800 & 1700 & 1800 \\
Capacitor cost, \$ & $35,442.96$ & $26,349.56$ & 25.85 & 401.05 & 446.70 \\
Total annual cost & - & 9093.39 & $25,540.00$ & $23,966.65$ & $23,881.02$ \\
Net saving, \$ & - & 25.65 & 9902.95 & $11,476.31$ & $11,561.94$ \\
\% saving & 0.9037 (bus 18) & 0.9518 (bus 18) & 0.9339 (bus 18) & 0.9348 (bus 18) & 0.9339 (bus 18) \\
Minimum voltage, p.u. & 0.9970 (bus 2) & 0.9977 (bus 2) & 0.9976 (bus 2) & 0.9975 (bus 2) & 0.9976 (bus 2) \\
Maximum voltage, p.u. & & & & &
\end{tabular}

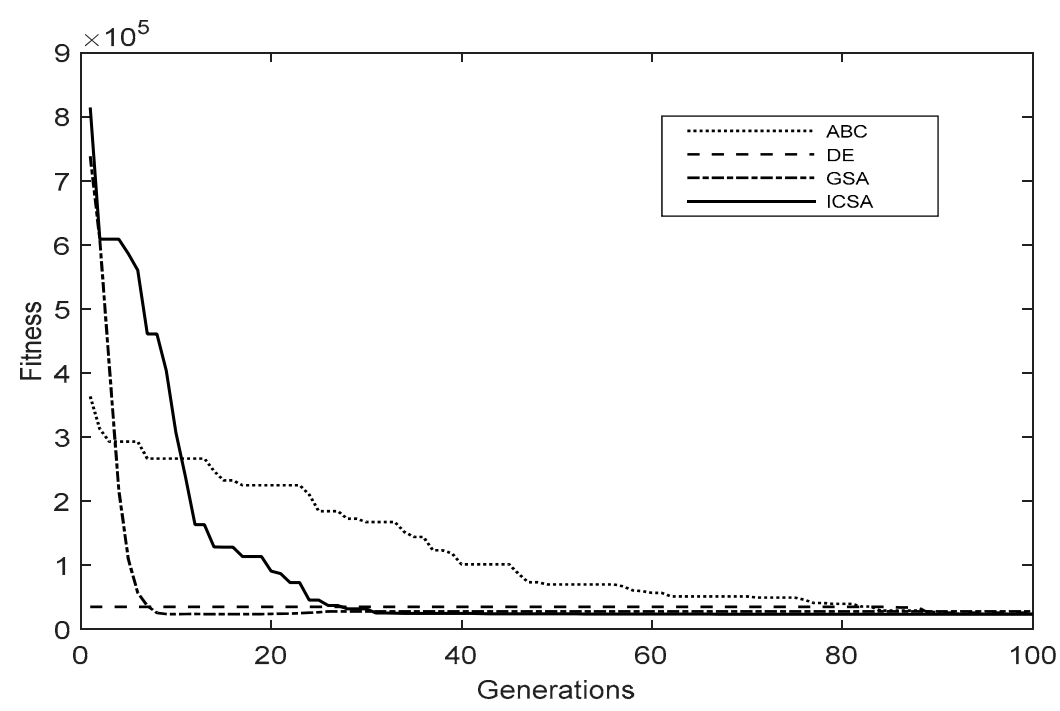

Figure 10. Convergence comparison 33-bus.

\section{CSA vs. ICSA}

This section presents a direct comparison between original crow search algorithm (CSA) and the proposed method (ICSA). The 33-bus network is analyzed by CSA as is presented in [14] where the buses 11, 24, 30 and 33 are taken as candidates and the capacitor sizes and their kVar values are shown in Table 12.

Table 12. Possible capacitor sizes and cost $(\$ / \mathrm{kVAr})$.

\begin{tabular}{ccccccc}
\hline $\mathbf{j}$ & $\mathbf{1}$ & $\mathbf{2}$ & $\mathbf{3}$ & $\mathbf{4}$ & $\mathbf{5}$ & $\mathbf{6}$ \\
\hline $\mathrm{Q}$ & 150 & 300 & 450 & 600 & 750 & 900 \\
\$/kVAr & 0.500 & 0.350 & 0.253 & 0.220 & 0.276 & 0.183 \\
\hline
\end{tabular}


The results obtained from the both algorithms are compared in Table 13. The table shows that the ICSA is capable to obtain accurate results than the original version CSA.

Table 13. Experiment result of ICSA over CSA in 33-bus system.

\begin{tabular}{cccc}
\hline Items Algorithms & Base Case & CSA & ICSA \\
\cline { 3 - 4 } & & 139.30 & 138.14 \\
& 210.97 & $23,402.40$ & $23,207.52$ \\
Total Power Losses $\left(P_{\text {LOSS }}\right), \mathrm{kW}$ & $35,442.96$ & $11,24,30,33$ & $11,24,30,33$ \\
Total Power losses cost, $\$$ & - & $600,450,600,300$ & $450,450,900,150$ \\
Optimal buses & - & 1950 & 1950 \\
Optimal capacitor size & - & 482.85 & 467.40 \\
Total kVAr & - & $23,885.25$ & $23,674.92$ \\
Capacitor cost, $\$$ & $35,442.96$ & $11,557.71$ & $11,768.04$ \\
Total annual cost & - & 32.60 & 33.20 \\
Net saving, \$ & - & 0.9336 (bus 18) & 0.9302 (bus 18) \\
\% saving & 0.9037 (bus 18) & 0.9976 (bus 2) & 0.9976 (bus 2) \\
Minimum voltage, p.u. & 0.9970 (bus 2) &
\end{tabular}

\subsubsection{9-Bus System}

For the third capacitor allocation experiment a network of 68 buses and 69 lines is analyzed. Before to install any capacitor, the network presents a total active power loss of $225 \mathrm{~kW}$, a total active and reactive power load of $3801.89 \mathrm{~kW}$ and $2693.60 \mathrm{kVAr}$. The annual cost for the corresponding $225 \mathrm{~kW}$ power loss is $\$ 37,800.00$. The system presents a minimum voltage of 0.9091 p.u. at the 64 th bus and a maximum 0.9999 p.u. at 2nd bus. As in the 10 and 33 bus experiments, the possible capacitor sizes and the price per kVAr is shown in the Table 8. The network diagram is illustrated in Figure 11 and the line and load data is presented in Table A3 in the Appendix A.

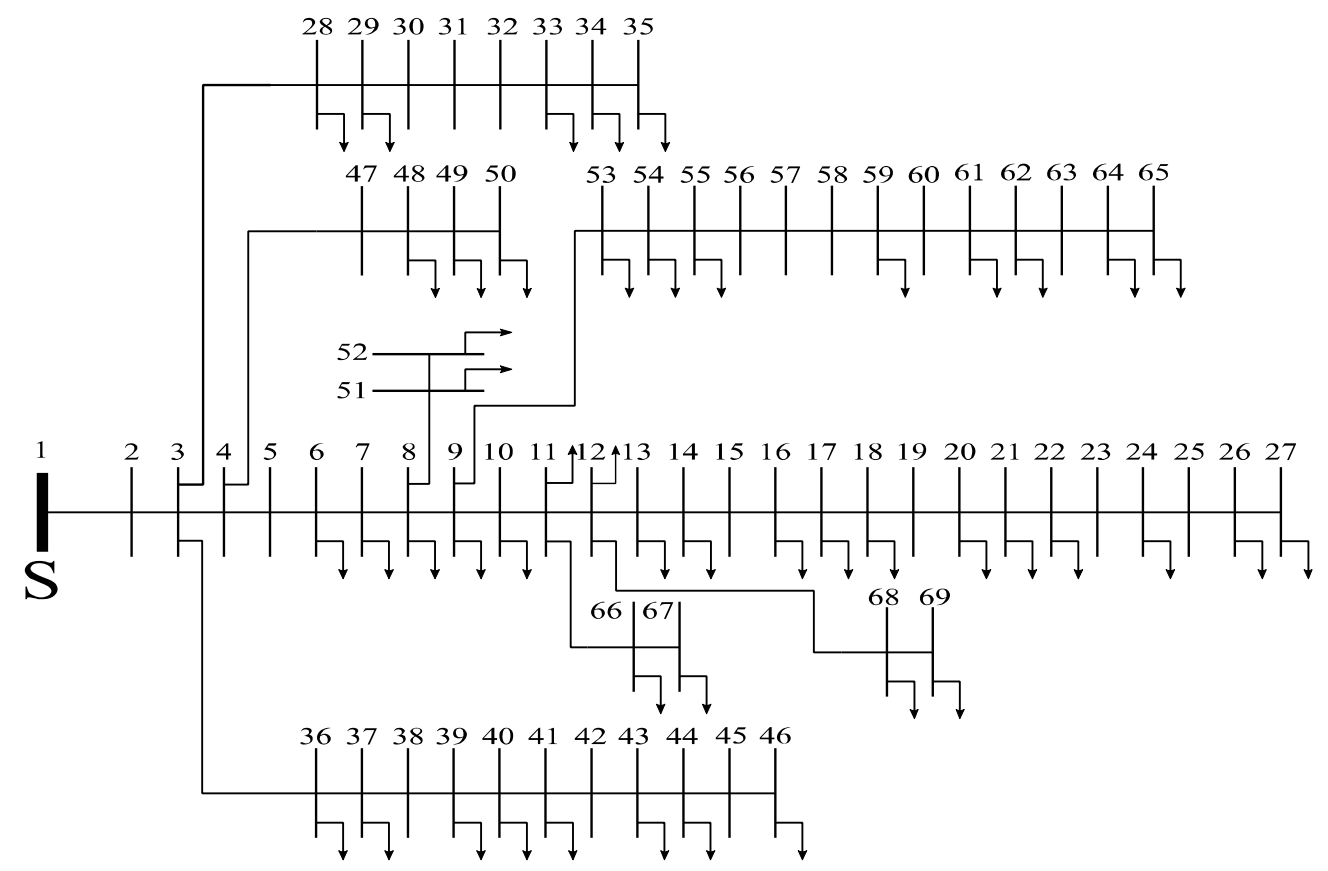

Figure 11. 69-Bus distribution test system. 
Using the ICSA method, optimal buses selected are the 57, 61 and 18 with the capacitor values of $150,1200,350 \mathrm{kVAr}$ respectively. With this reactance adjustment the total power loss is reduced from 225 to $146.20 \mathrm{~kW}$, saving $33.96 \%$ from the original cost. The voltage profile presents a minimum of 0.9313 p.u. at bus 65 th and a maximum of 0.9999 2nd. Table 14 shows a detailed comparison between the results obtained by the proposed method and the results of the DE, ABC and GSA algorithms.

Table 14. Experiment result of 69-bus system.

\begin{tabular}{|c|c|c|c|c|c|}
\hline Items Algorithms & Base Case & \multicolumn{4}{|c|}{ Compensated } \\
\hline Total Power Losses $\left(P_{\text {LOSS }}\right), \mathrm{kW}$ & 225 & 210.02 & 149.36 & 147.1017 & 146.20 \\
\hline Optimal buses & - & $57,58,64,21,63,20,62,26$ & $58,59,62,24$ & $61,27,22$ & $57,61,18$ \\
\hline Optimal capacitor size & - & $\begin{array}{c}750,600,900,350,150,150 \\
350,150\end{array}$ & $\begin{array}{l}150,150,900 \\
150\end{array}$ & $1200,150,150$ & $150,1200,350$ \\
\hline Total annual cost & $37,800.00$ & $36,257.06$ & $25,482.18$ & $25,066.8$ & $24,961.10$ \\
\hline Net saving, $\$$ & - & 1542.94 & $12,317.82$ & $12,733.20$ & $12,836.90$ \\
\hline$\%$ saving & - & 4.08 & 32.58 & 33.69 & 33.96 \\
\hline Minimum voltage, p.u. & 0.9091 (bus 65) & 0.9504 (bus 61) & 0.9287 (bus 65) & 0.9298 (bus 65) & 0.9313 (bus 65) \\
\hline Maximum voltage, p.u. & 0.9999 (bus 2) & 0.9999 (bus 2) & 0.9999 (bus 2) & 0.9999 (bus 2) & 0.9999 (bus 2) \\
\hline
\end{tabular}

\subsubsection{Statistical Analysis}

In order to validate the results a statistical analysis between the different methods is performed and the results are illustrated in Table 15.

Table 15. Statistical Analysis.

\begin{tabular}{cccc}
\hline Wilcoxon & DE-ICSA & ABC-ICSA & GSA-ICSA \\
\hline 10-Bus & $2.5576 \times 10^{-34}$ & $2.4788 \times 10^{-34}$ & $2.5566 \times 10^{-34}$ \\
33-Bus & $6.1019 \times 10^{-34}$ & $3.4570 \times 10^{-32}$ & $7.6490 \times 10^{-24}$ \\
69-Bus & $1.0853 \times 10^{-29}$ & $8.6857 \times 10^{-28}$ & $3.6802 \times 10^{-20}$ \\
\hline
\end{tabular}

\section{Conclusions}

In this paper, an improved version of the CSA method is presented to solve complex high multi-modal optimization problems of energy: Identification of induction motors and capacitor allocation in distribution networks. In the new algorithm, two features of the original CSA are modified: (I) the awareness probability (AP) and (II) the random perturbation. With the purpose to enhance the exploration-exploitation ratio the fixed awareness probability (AP) value is replaced (I) by a dynamic awareness probability (DAP), which is adjusted according to the fitness value of each candidate solution. The Lévy flight movement is also incorporated to enhance the search capacities of the original random perturbation (II) of CSA. With such adaptations, the new approach preserves solution diversity and improves the convergence to difficult high multi-modal optima.

In order to evaluate its performance, the proposed algorithm has been compared with other popular search algorithms such as the DE, ABC and GSA. The results demonstrate the high performance of the proposed method in terms of accuracy and robustness.

Author Contributions: Primitivo Díaz and Erik Cuevas wrote the paper. Primitivo Díaz and Omar Avalos proposed the methodology and designed the experiments to implement. Jorge Gálvez and Salvador Hinojosa performed the experiments. Marco Pérez-Cisneros and Daniel Zaldivar analyzed the results of the experiments.

Conflicts of Interest: The authors declare no conflict of interest. 


\section{Appendix A. Systems Data}

Table A1. 10-bus test system data.

\begin{tabular}{ccccccc}
\hline Line No. & From Bus $\boldsymbol{i}$ & To Bus $\boldsymbol{i + 1}$ & $\boldsymbol{R}(\boldsymbol{\Omega})$ & $\boldsymbol{X}(\boldsymbol{\Omega})$ & $\boldsymbol{P}_{\boldsymbol{L}}(\mathbf{k W})$ & $\boldsymbol{Q}_{\boldsymbol{L}}(\mathbf{k V A R})$ \\
\hline 1 & 1 & 2 & 1.35309 & 1.3235 & 1840 & 460 \\
2 & 2 & 3 & 1.17024 & 1.1446 & 980 & 340 \\
3 & 3 & 4 & 0.84111 & 0.8227 & 1790 & 446 \\
4 & 4 & 5 & 1.52348 & 1.0276 & 1598 & 1840 \\
5 & 2 & 9 & 2.01317 & 1.3579 & 1610 & 600 \\
6 & 9 & 10 & 1.68671 & 1.1377 & 780 & 110 \\
7 & 2 & 6 & 2.55727 & 1.7249 & 1150 & 60 \\
8 & 6 & 7 & 1.0882 & 0.7340 & 980 & 130 \\
9 & 6 & 8 & 1.25143 & 0.8441 & 1640 & 200 \\
\hline
\end{tabular}

Table A2. 33-bus test system data.

\begin{tabular}{|c|c|c|c|c|c|c|}
\hline Line No. & From Bus $i$ & To Bus $i+1$ & $R(\Omega)$ & $X(\Omega)$ & $P_{L}(\mathrm{~kW})$ & $Q_{L}$ (kVAR) \\
\hline 1 & 1 & 2 & 0.0922 & 0.0477 & 100 & 60 \\
\hline 2 & 2 & 3 & 0.4930 & 0.2511 & 90 & 40 \\
\hline 3 & 3 & 4 & 0.3660 & 0.1864 & 120 & 80 \\
\hline 4 & 4 & 5 & 0.3811 & 0.1941 & 60 & 30 \\
\hline 5 & 5 & 6 & 0.8190 & 0.7070 & 60 & 20 \\
\hline 6 & 6 & 7 & 0.1872 & 0.6188 & 200 & 100 \\
\hline 7 & 7 & 8 & 1.7114 & 1.2351 & 200 & 100 \\
\hline 8 & 8 & 9 & 1.0300 & 0.7400 & 60 & 20 \\
\hline 9 & 9 & 10 & 1.0400 & 0.7400 & 60 & 20 \\
\hline 10 & 10 & 11 & 0.1966 & 0.0650 & 45 & 30 \\
\hline 11 & 11 & 12 & 0.3744 & 0.1238 & 60 & 35 \\
\hline 12 & 12 & 13 & 1.4680 & 1.1550 & 60 & 35 \\
\hline 13 & 13 & 14 & 0.5416 & 0.7129 & 120 & 80 \\
\hline 14 & 14 & 15 & 0.5910 & 0.5260 & 60 & 10 \\
\hline 15 & 15 & 16 & 0.7463 & 0.5450 & 60 & 20 \\
\hline 16 & 16 & 17 & 1.2890 & 1.7210 & 60 & 20 \\
\hline 17 & 17 & 18 & 0.7320 & 0.5740 & 90 & 40 \\
\hline 18 & 2 & 19 & 0.1640 & 0.1565 & 90 & 40 \\
\hline 19 & 19 & 20 & 1.5042 & 1.3554 & 90 & 40 \\
\hline 20 & 20 & 21 & 0.4095 & 0.4784 & 90 & 40 \\
\hline 21 & 21 & 22 & 0.7089 & 0.9373 & 90 & 40 \\
\hline 22 & 3 & 23 & 0.4512 & 0.3083 & 90 & 50 \\
\hline 23 & 23 & 24 & 0.8980 & 0.7091 & 420 & 200 \\
\hline 24 & 24 & 25 & 0.8960 & 0.7011 & 420 & 200 \\
\hline 25 & 6 & 26 & 0.2030 & 0.1034 & 60 & 25 \\
\hline 26 & 26 & 27 & 0.2842 & 0.1447 & 60 & 25 \\
\hline 27 & 27 & 28 & 1.0590 & 0.9337 & 60 & 20 \\
\hline 28 & 28 & 29 & 0.8042 & 0.7006 & 120 & 70 \\
\hline 29 & 29 & 30 & 0.5075 & 0.2585 & 200 & 600 \\
\hline 30 & 30 & 31 & 0.9744 & 0.9630 & 150 & 70 \\
\hline 31 & 31 & 32 & 0.3105 & 0.3619 & 210 & 100 \\
\hline 32 & 32 & 33 & 0.3410 & 0.5302 & 60 & 40 \\
\hline
\end{tabular}


Table A3. 69-bus test system data.

\begin{tabular}{|c|c|c|c|c|c|c|}
\hline Line No. & From Bus $i$ & To Bus $i+1$ & $R(\Omega)$ & $X(\Omega)$ & $P_{L}(\mathrm{~kW})$ & $Q_{L}(\mathrm{kVAR})$ \\
\hline 1 & 1 & 2 & 0.00050 & 0.0012 & 0.00 & 0.00 \\
\hline 2 & 2 & 3 & 0.00050 & 0.0012 & 0.00 & 0.00 \\
\hline 3 & 3 & 4 & 0.00150 & 0.0036 & 0.00 & 0.00 \\
\hline 4 & 4 & 5 & 0.02510 & 0.0294 & 0.00 & 0.00 \\
\hline 5 & 5 & 6 & 0.36600 & 0.1864 & 2.60 & 2.20 \\
\hline 6 & 6 & 7 & 0.38100 & 0.1941 & 40.40 & 30.00 \\
\hline 7 & 7 & 8 & 0.09220 & 0.0470 & 75.00 & 54.00 \\
\hline 8 & 8 & 9 & 0.04930 & 0.0251 & 30.00 & 22.00 \\
\hline 9 & 9 & 10 & 0.81900 & 0.2707 & 28.00 & 19.00 \\
\hline 10 & 10 & 11 & 0.18720 & 0.0619 & 145.00 & 104.00 \\
\hline 11 & 11 & 12 & 0.71140 & 0.2351 & 145.00 & 104.00 \\
\hline 12 & 12 & 13 & 1.03000 & 0.3400 & 8.00 & 5.00 \\
\hline 13 & 13 & 14 & 1.04400 & 0.3400 & 8.00 & 5.00 \\
\hline 14 & 14 & 15 & 1.05800 & 0.3496 & 0.00 & 0.00 \\
\hline 15 & 15 & 16 & 0.19660 & 0.0650 & 45.00 & 30.00 \\
\hline 16 & 16 & 17 & 0.37440 & 0.1238 & 60.00 & 35.00 \\
\hline 17 & 17 & 18 & 0.00470 & 0.0016 & 60.00 & 35.00 \\
\hline 18 & 18 & 19 & 0.32760 & 0.1083 & 0.00 & 0.00 \\
\hline 19 & 19 & 20 & 0.21060 & 0.0690 & 1.00 & 0.60 \\
\hline 20 & 20 & 21 & 0.34160 & 0.1129 & 114.00 & 81.00 \\
\hline 21 & 21 & 22 & 0.01400 & 0.0046 & 5.00 & 3.50 \\
\hline 22 & 22 & 23 & 0.15910 & 0.0526 & 0.00 & 0.00 \\
\hline 23 & 23 & 24 & 0.34630 & 0.1145 & 28.00 & 20.00 \\
\hline 24 & 24 & 25 & 0.74880 & 0.2475 & 0.00 & 0.00 \\
\hline 25 & 25 & 26 & 0.30890 & 0.1021 & 14.00 & 10.00 \\
\hline 26 & 26 & 27 & 0.17320 & 0.0572 & 14.00 & 10.00 \\
\hline 27 & 3 & 28 & 0.00440 & 0.0108 & 26.00 & 18.60 \\
\hline 28 & 28 & 29 & 0.06400 & 0.1565 & 26.00 & 18.60 \\
\hline 29 & 29 & 30 & 0.39780 & 0.1315 & 0.00 & 0.00 \\
\hline 30 & 30 & 31 & 0.07020 & 0.0232 & 0.00 & 0.00 \\
\hline 31 & 31 & 32 & 0.35100 & 0.1160 & 0.00 & 0.00 \\
\hline 32 & 32 & 33 & 0.83900 & 0.2816 & 14.00 & 10.00 \\
\hline 33 & 33 & 34 & 1.70800 & 0.5646 & 19.50 & 14.00 \\
\hline 34 & 34 & 35 & 1.47400 & 0.4873 & 6.00 & 4.00 \\
\hline 35 & 3 & 36 & 0.00440 & 0.0108 & 26.00 & 18.55 \\
\hline 36 & 36 & 37 & 0.06400 & 0.1565 & 26.00 & 18.55 \\
\hline 37 & 37 & 38 & 0.10530 & 0.1230 & 0.00 & 0.00 \\
\hline 38 & 38 & 39 & 0.03040 & 0.0355 & 24.00 & 17.00 \\
\hline 39 & 39 & 40 & 0.00180 & 0.0021 & 24.00 & 17.00 \\
\hline 40 & 40 & 41 & 0.72830 & 0.8509 & 1.20 & 1.00 \\
\hline 41 & 41 & 42 & 0.31000 & 0.3623 & 0.00 & 0.00 \\
\hline 42 & 42 & 43 & 0.04100 & 0.0478 & 6.00 & 4.30 \\
\hline 43 & 43 & 44 & 0.00920 & 0.0116 & 0.00 & 0.00 \\
\hline 44 & 44 & 45 & 0.10890 & 0.1373 & 39.22 & 26.30 \\
\hline 45 & 45 & 46 & 0.00090 & 0.0012 & 39.22 & 26.30 \\
\hline 46 & 4 & 47 & 0.00340 & 0.0084 & 0.00 & 0.00 \\
\hline 47 & 47 & 48 & 0.08510 & 0.2083 & 79.00 & 56.40 \\
\hline 48 & 48 & 49 & 0.28980 & 0.7091 & 384.70 & 274.50 \\
\hline 49 & 49 & 50 & 0.08220 & 0.2011 & 384.70 & 274.50 \\
\hline 50 & 8 & 51 & 0.09280 & 0.0473 & 40.50 & 28.30 \\
\hline 51 & 51 & 52 & 0.33190 & 0.1140 & 3.60 & 2.70 \\
\hline 52 & 9 & 53 & 0.17400 & 0.0886 & 4.35 & 3.50 \\
\hline 53 & 53 & 54 & 0.20300 & 0.1034 & 26.40 & 19.00 \\
\hline 54 & 54 & 55 & 0.28420 & 0.1447 & 24.00 & 17.20 \\
\hline 55 & 55 & 56 & 0.28130 & 0.1433 & 0.00 & 0.00 \\
\hline 56 & 56 & 57 & 1.59000 & 0.5337 & 0.00 & 0.00 \\
\hline 57 & 57 & 58 & 0.78370 & 0.2630 & 0.00 & 0.00 \\
\hline
\end{tabular}


Table A3. Cont.

\begin{tabular}{ccccccc}
\hline Line No. & From Bus $i$ & To Bus $i+\mathbf{1}$ & $\boldsymbol{R}(\boldsymbol{\Omega})$ & $\boldsymbol{X}(\boldsymbol{\Omega})$ & $\boldsymbol{P}_{\boldsymbol{L}}(\mathbf{k W})$ & $\boldsymbol{Q}_{L}(\mathbf{k V A R})$ \\
\hline 58 & 58 & 59 & 0.30420 & 0.1006 & 100.00 & 72.00 \\
59 & 59 & 60 & 0.38610 & 0.1172 & 0.00 & 0.00 \\
60 & 60 & 61 & 0.50750 & 0.2585 & 1244.00 & 888.00 \\
61 & 61 & 62 & 0.09740 & 0.0496 & 32.00 & 23.00 \\
62 & 62 & 63 & 0.14500 & 0.0738 & 0.00 & 0.00 \\
63 & 63 & 64 & 0.71050 & 0.3619 & 227.00 & 162.00 \\
64 & 64 & 65 & 1.04100 & 0.5302 & 59.00 & 42.00 \\
65 & 11 & 66 & 0.20120 & 0.0611 & 18.00 & 13.00 \\
66 & 66 & 67 & 0.00470 & 0.0014 & 18.00 & 13.00 \\
67 & 12 & 68 & 0.73940 & 0.2444 & 28.00 & 20.00 \\
68 & 68 & 69 & 0.00470 & 0.0016 & 28.00 & 20.00 \\
\hline
\end{tabular}

\section{References}

1. Prakash, V.; Baskar, S.; Sivakumar, S.; Krishna, K.S. A novel efficiency improvement measure in three-phase induction motors, its conservation potential and economic analysis. Energy Sustain. Dev. 2008, 12, 78-87. [CrossRef]

2. Saidur, R. A review on electrical motors energy use and energy savings. Renew. Sustain. Energy Rev. 2010, 14, 877-898. [CrossRef]

3. Perez, I.; Gomez-Gonzalez, M.; Jurado, F. Estimation of induction motor parameters using shuffled frog-leaping algorithm. Electr. Eng. 2013, 95, 267-275. [CrossRef]

4. Sakthivel, V.P.; Bhuvaneswari, R.; Subramanian, S. Artificial immune system for parameter estimation of induction motor. Expert Syst. Appl. 2010, 37, 6109-6115. [CrossRef]

5. Lee, S.; Grainger, J. Optimum Placement of Fixed and Switched Capacitors on Primary Distribution Feeders. IEEE Trans. Power Appar. Syst. 1981, 345-352. [CrossRef]

6. Zidar, M.; Georgilakis, P.S.; Hatziargyriou, N.D.; Capuder, T.; Škrlec, D. Review of energy storage allocation in power distribution networks: Applications, methods and future research. IET Gener. Transm. Distrib. 2016, 3, 645-652. [CrossRef]

7. Grainger, J.; Lee, S. Optimum Size and Location of Shunt Capacitors for Reduction of Losses on Distribution Feeders. IEEE Trans. Power Appar. Syst. 1981, 3, 1105-1118. [CrossRef]

8. Neagle, N.M.; Samson, D.R. Loss Reduction from Capacitors Installed on Primary Feeders. Trans. Am. Inst. Electr. Eng. Part III Power Appar. Syst. 1956, 75, 950-959. [CrossRef]

9. Dura, H. Optimum Number, Location, and Size of Shunt Capacitors in Radial Distribution Feeders A Dynamic Programming Approach. IEEE Trans. Power Appar. Syst. 1968, 9, 1769-1774. [CrossRef]

10. Hogan, P.M.; Rettkowski, J.D.; Bala, J.L. Optimal capacitor placement using branch and bound. In Proceedings of the 37th Annual North American Power Symposium, Ames, IA, USA, 25 October 2005; pp. 84-89. [CrossRef]

11. Mekhamer, S.F.; El-Hawary, M.E.; Soliman, S.A.; Moustafa, M.A.; Mansour, M.M. New heuristic strategies for reactive power compensation of radial distribution feeders. IEEE Trans. Power Deliv. 2002, 17, 1128-1135. [CrossRef]

12. Da Silva, I.C.; Carneiro, S.; de Oliveira, E.J.; de Souza Costa, J.; Pereira, J.L.R.; Garcia, P.A.N. A Heuristic Constructive Algorithm for Capacitor Placement on Distribution Systems. IEEE Trans. Power Syst. 2008, 23, 1619-1626. [CrossRef]

13. Chis, M.; Salama, M.M.A.; Jayaram, S. Capacitor placement in distribution systems using heuristic search strategies. IEE Proc. Gener. Transm. Distrib. 1997, 144, 225. [CrossRef]

14. Askarzadeh, A. Capacitor placement in distribution systems for power loss reduction and voltage improvement: A new methodology. IET Gener. Transm. Distrib. 2016, 10, 3631-3638. [CrossRef]

15. Ng, H.N.; Salama, M.M.A.; Chikhani, A.Y. Classification of capacitor allocation techniques. IEEE Trans. Power Deliv. 2000, 15, 387-392. [CrossRef]

16. Jordehi, A.R. Optimisation of electric distribution systems: A review. Renew. Sustain. Energy Rev. 2015, 51, 1088-1100. [CrossRef] 
17. Aman, M.M.; Jasmon, G.B.; Bakar, A.H.A.; Mokhlis, H.; Karimi, M. Optimum shunt capacitor placement in distribution system-A review and comparative study. Renew. Sustain. Energy Rev. 2014, 30, 429-439. [CrossRef]

18. Avalos, O.; Cuevas, E.; Gálvez, J. Induction Motor Parameter Identification Using a Gravitational Search Algorithm. Computers 2016, 5, 6. [CrossRef]

19. Mohamed Shuaib, Y.; Surya Kalavathi, M.; Christober Asir Rajan, C. Optimal capacitor placement in radial distribution system using Gravitational Search Algorithm. Int. J. Electr. Power Energy Syst. 2015, 64, 384-397. [CrossRef]

20. Sakthivel, V.P.; Bhuvaneswari, R.; Subramanian, S. An accurate and economical approach for induction motor field efficiency estimation using bacterial foraging algorithm. Measurement 2011, 44, 674-684. [CrossRef]

21. Devabalaji, K.R.; Ravi, K.; Kothari, D.P. Optimal location and sizing of capacitor placement in radial distribution system using Bacterial Foraging Optimization Algorithm. Int. J. Electr. Power Energy Syst. 2015, 71, 383-390. [CrossRef]

22. Picardi, C.; Rogano, N. Parameter identification of induction motor based on particle swarm optimization. In Proceedings of the International Symposium on Power Electronics, Electrical Drives, Automation and Motion, Taormina, Italy, 23-26 May 2006; pp. 968-973. [CrossRef]

23. Singh, S.P.; Rao, A.R. Optimal allocation of capacitors in distribution systems using particle swarm optimization. Int. J. Electr. Power Energy Syst. 2012, 43, 1267-1275. [CrossRef]

24. Prakash, K.; Sydulu, M. Particle Swarm Optimization Based Capacitor Placement on Radial Distribution Systems. In Proceedings of the 2007 IEEE Power Engineering Society General Meeting, Tampa, FL, USA, 24-28 June 2017; pp. 1-5. [CrossRef]

25. Lee, C.-S.; Ayala, H.V.H.; dos Santos Coelho, L. Capacitor placement of distribution systems using particle swarm optimization approaches. Int. J. Electr. Power Energy Syst. 2015, 64, 839-851. [CrossRef]

26. Alonge, F.; D'Ippolito, F.; Ferrante, G.; Raimondi, F. Parameter identification of induction motor model using genetic algorithms. IEE Proc. Control Theory Appl. 1998, 145, 587-593. [CrossRef]

27. Swarup, K. Genetic algorithm for optimal capacitor allocation in radial distribution systems. In Proceedings of the 6th WSEAS international conference on evolutionary, Lisbon, Portugal, 16-18 June 2005.

28. Ursem, R.; Vadstrup, P. Parameter identification of induction motors using differential evolution. In Proceedings of the 2003 Congress on Evolutionary Computation, Canberra, ACT, Australia, 8-12 December 2003.

29. Su, C.; Lee, C. Modified differential evolution method for capacitor placement of distribution systems. In Proceedings of the IEEE Transmission and Distribution Conference and Exhibition 2002: Asia Pacific, Yokohama, Japan, 6-10 October 2002.

30. Chiou, J.; Chang, C.; Su, C. Capacitor placement in large-scale distribution systems using variable scaling hybrid differential evolution. Int. J. Electr. Power 2006, 28, 739-745. [CrossRef]

31. Huang, Y.-C.; Yang, H.T.; Huang, C.L. Solving the capacitor placement problem in a radial distribution system using Tabu Search approach. IEEE Trans. Power Syst. 1996, 11, 1868-1873. [CrossRef]

32. Olaimaei, J.; Moradi, M.; Kaboodi, T. A new adaptive modified firefly algorithm to solve optimal capacitor placement problem. In Proceedings of the 2013 18th Conference on Electr Power Distribution Networks, Kermanshah, Iran, 30 April-1 May 2013.

33. Askarzadeh, A. A novel metaheuristic method for solving constrained engineering optimization problems: Crow search algorithm. Comput. Struct. 2016, 169, 1-12. [CrossRef]

34. Oliva, D.; Hinojosa, S.; Cuevas, E.; Pajares, G.; Avalos, O.; Gálvez, J. Cross entropy based thresholding for magnetic resonance brain images using Crow Search Algorithm. Expert Syst. Appl. 2017, 79, 164-180. [CrossRef]

35. Liu, D.; Liu, C.; Fu, Q.; Li, T.; Imran, K.; Cui, S.; Abrar, F. ELM evaluation model of regional groundwater quality based on the crow search algorithm. Ecol. Indic. 2017, 81, 302-314. [CrossRef]

36. Emery, N.J.; Clayton, N.S. The Mentality of Crows: Convergent Evolution of Intelligence in Corvids and Apes. Science 2004, 306, 1903-1907. [CrossRef] [PubMed]

37. Holzhaider, J.C.; Hunt, G.R.; Gray, R.D. Social learning in New Caledonian crows. Learn. Behav. 2010, 38, 206-219. [CrossRef] [PubMed] 
38. Rajput, S.; Parashar, M.; Dubey, H.M.; Pandit, M. Optimization of benchmark functions and practical problems using Crow Search Algorithm. In Proceedings of the 2016 Fifth International Conference on Eco-friendly Computing and Communication Systems (ICECCS), Bhopal, India, 8-9 December 2016; pp. 73-78. [CrossRef]

39. Karaboga, D.; Basturk, B. A powerful and efficient algorithm for numerical function optimization: Artificial bee colony (ABC) algorithm. J. Glob. Optim. 2007, 39, 459-471. [CrossRef]

40. Baronchelli, A.; Radicchi, F. Lévy flights in human behavior and cognition. Chaos Solitons Fractals 2013, 56, 101-105. [CrossRef]

41. Sotolongo-Costa, O.; Antoranz, J.C.; Posadas, A.; Vidal, F.; Vazquez, A. Levy Flights and Earthquakes. Geophys. Res. Lett. 2000, 27, 1965-1968. [CrossRef]

42. Shlesinger, M.F.; Zaslavsky, G.M.; Frisch, U. Lévy Flights and Related Topics in Physics; Springer: Berlin, Germany, 1995.

43. Yang, X.-S.; Ting, T.O.; Karamanoglu, M. Random Walks, Lévy Flights, Markov Chains and Metaheuristic Optimization; Springer: Dordrecht, The Netherlands, 2013; pp. 1055-1064. [CrossRef]

44. Yang, X.-S. Nature-Inspired Metaheuristic Algorithms; Luniver Press: Beckington, UK, 2010.

45. Venkatesh, B.; Ranjan, R. Data structure for radial distribution system load flow analysis. IEE Proc. Gener. Transm. Distrib. 2003, 150, 101-106. [CrossRef]

46. Chen, T.; Chen, M.; Hwang, K. Distribution system power flow analysis-a rigid approach. IEEE Trans. Power Deliv. 1991, 6, 1146-1152. [CrossRef]

47. Ghosh, S.; Das, D. Method for load-flow solution of radial distribution networks. Gener. Transm. Distrib. 1999, 146, 641-648. [CrossRef]

48. Rao, R.S.; Narasimham, S.V.L.; Ramalingaraju, M. Optimal capacitor placement in a radial distribution system using Plant Growth Simulation Algorithm. Int. J. Electr. Power Energy Syst. 2011, 33, 1133-1139. [CrossRef]

49. Jamadi, M.; Merrikh-Bayat, F. New Method for Accurate Parameter Estimation of Induction Motors Based on Artificial Bee Colony Algorithm. arXiv 2014, arXiv:1402.4423

50. Grainger, J.J.; Lee, S.H. Capacity Release by Shunt Capacitor Placement on Distribution Feeders: A New Voltage-Dependent Model. IEEE Trans. Power Appar. Syst. 1982, 5, 1236-1244. [CrossRef]

51. Baran, M.E.; Wu, F.F. Network reconfiguration in distribution systems for loss reduction and load balancing. IEEE Trans. Power Deliv. 1989, 4, 1401-1407. [CrossRef]

52. Baran, M.; Wu, F.F. Optimal sizing of capacitors placed on a radial distribution system. IEEE Trans. Power Deliv. 1989, 4, 735-743. [CrossRef]

(C) 2018 by the authors. Licensee MDPI, Basel, Switzerland. This article is an open access article distributed under the terms and conditions of the Creative Commons Attribution (CC BY) license (http:/ / creativecommons.org/licenses/by/4.0/). 